\title{
Mothers' Experiences of Parenting a Child with Dyslexia: A Case Study in Sri Lanka
}

\author{
Samudra Senarath \\ Department of Educational Psychology, Faculty of Education, University of Colombo, Sri Lanka
}

\begin{abstract}
This study focuses on the psycho-social experiences faced by the mothers of dyslexic children. It is often the mothers who spend the most amount of time with their children after they are born and mothers generally play an important role in providing a good learning environment. Studies have shown that mothers have higher levels of stress than fathers, because mothers assume a greater share of the burden of responsibility in raising children with disabilities. The objectives of this study were to identify the factors influencing the level of psychological stress experienced by mothers of children with dyslexia; to evaluate their emotional experiences and determine their level of life satisfaction. Fifteen mothers of dyslexic children and fifteen mothers of non-dyslexic children were selected from the same classroom (grades 5-8, ages 10-14), for a sample survey with purposive sampling. The study employed unstructured interviews and a questionnaire with a self-developed screening test for psychosocial issues and the mothers' emotional experiences. The Parental Stress Scale (Berry \& Jones, 1995) with an 18 item self-report scale was also utilized. The results showed that the mothers of dyslexic children had a higher level of negative emotions about their children's nature, education and future compared to the mothers of non-dyslexic children. The mothers of dyslexic children also presented a moderate level of stress scores and associated stress factors included insufficient mutual support within the family, the class teachers' influence in school, difficulty in accepting reality, social isolation, problems with educating the child, problems with memory and being required to do the child's homework. These stress factors were high in contrast to the mothers of non-dyslexic children. Regarding the scores relating to the parents' life satisfaction with their child, the responses showed very low scores for the mothers of dyslexic children, who had negative attitudes and faced more social stigma than the mothers of non-dyslexic children. The findings indicated that the mothers of dyslexic children needed support and assistance to overcome their challenges and to enhance their coping strategies, in order to protect and nurture their children. These mothers need support from multidisciplinary health professionals who could provide assistance in the form of counseling, psychotherapy, psychological skills, occupational therapy and psychiatric treatment, which could help in parenting children with dyslexia. Teachers and special education teachers should offer support to these children and their parents, to help them manage and overcome their difficulties with reading, writing and learning.
\end{abstract}

Keywords: emotional experiences, psychological stress, life satisfaction, mothers, dyslexia.

\section{INTRODUCTION}

$\mathrm{D}$ yslexia is a lifelong disability and it is sometimes called the 'hidden disability' because it has no physically visible signs that can easily be detected. The most common symptoms of a dyslexic child are difficulties in learning and speaking, as well as difficulties with phonological processing like the manipulation of sounds and spellings, despite having an average or above-average intelligence quotient. A dyslexic child may also show a low performance in phonological memory and vocabulary, resulting in poor social skills and a short concentration span (Campbell \& Butterworth, 1985). Therefore, most dyslexic children face many difficulties in their educational interactions and social surroundings (Dyson, 1997). Studies show that besides these difficulties, dyslexic children may suffer frustration and low self-esteem because of their lack of achievement, particularly in academic work, which could affect their long-term life opportunities. Thus, the literature reports that parenting a child with dyslexia can be traumatic. The parents' understanding of dyslexia and its impact on their children is critical in ensuring their children's sustainable development. In Sri Lanka, dyslexia has a prevalence of around $6 \%$ and most parents do not know much about dyslexia and its symptoms. This leads to the problem of dyslexic children not receiving the specialized treatment they need such as attending extra classes with special educators, and thus they do not have an equal opportunity to receive a good quality education. Therefore, the sooner dyslexic children are identified and diagnosed, the higher the chances of establishing proper methods of treatment including specialized learning and education, while lessening their parents' psycho-social issues (Hamid, 2012).

This study has a greater focus on mothers' psycho-social issues because mothers often spend the most amount of time with their children. In general, mothers play an important role in providing a good environment for learning. Studies have shown that the mothers of dyslexic children were found to have more stress than the fathers, because they bear a disproportionate share of the responsibilities of raising children with disabilities (Shyam \& Govil, 2014). Having children with dyslexia affects the mothers' personal life in many ways, including a reduced involvement in social and leisure activities, poor social relationships, the disruption of daily routines, health issues and a lack of motivation (Karande \& Kulkarni, 2009). Their activities are reduced as a result of their anxiety when thinking about their children's future. This is an additional responsibility especially for working mothers who have to deal with stressful work situations and hectic daily work schedules. Some mothers also experience negative emotions; frustration, anxiety, guilt, insecurity, emotional 
instability, self-pity and hopelessness, due to unfulfilled expectations for their children (Chandramuki, Venkatakrishnashastry \& Vranda, 2012). There can be other negative impacts on the parents' lives; they can experience excessive fatigue, lack of sleep, being unable to manage day to day activities and a high level of stress. The research problem of the study was to determine the psycho-social factors associated with mothers of dyslexic children and the impacts on their emotional well-being and life satisfaction. Accordingly, these objectives were formulated to the present study; to examine the mothers' emotional status and the nature of their life satisfaction, to identify their psychological stress and the different factors influencing the levels of stress experienced by mothers of dyslexic children and to examine the psycho-social experiences of mothers of children with dyslexia.

Main Hypothesis: The mothers of dyslexic children would have significant negative emotional experiences, psychological stress and lower life satisfaction in relating to their dyslexic child when contrasted with mothers of nondyslexic children.

\section{LITERATURE REVIEW}

Parental stress is defined as stress that parents experience not only because of child-rearing, but also due to their social and environmental circumstances, responsibilities and everyday life (Belsky, 1984). Dyslexia brings significant challenges and trauma, for the student and for the parents as well (Elliott, Nicolson \& Davis, 2016). Parents experience stress in coping with their child's apparent poor academic progress (Karande \& Kuril, 2011), particularly if they have no understanding of the nature of dyslexia and its characteristics. Mothers in particular, show high levels of stress and depression. Significant impacts are reported in families and there are increased difficulties in the everyday life of the parents (Bonifacci, Montuschi, Lami \& Snowling, 2014). Previous studies indicated that parents who are unaware of dyslexia often have negative feelings such as frustration, denial and stress when their children do not meet their expectations (Ozonoff, Dawson \& McPartland, 2002). Furthermore, these parents tend to experience anxiety and low self-esteem regarding their children's future life and academic performance. These behaviors not only affect the children but have a negative impact on their own life; i.e.: excessive fatigue, lack of sleep and stress. The most common maternal worries involve both emotional and practical difficulties (Earey, 2013), as their child's chronic poor performance at school relates to the child losing self-esteem, getting frustrated and anxious and developing withdrawn or aggressive behavior (Karande, Kumbhare, Kulkarni \& Shah, 2009). In addition, maternal anxiety is increased when attempting to seek appropriate help for their child (Earey, 2013). Mothers become emotionally and physically drained as they become heavily involved in their child's remedial education (Bonifacci et al., 2014) and worry for the child's future (Karande et al., 2009). Many mothers choose to quit their jobs to focus their energy and time on attending to their child (Poon-McBrayer \& McBrayer, 2014). Overall, the literature reports ongoing difficulties for parents as they struggle to support their child before, during and after an assessment of dyslexia (Earey, 2013). Mothers in particular have to face emotional problems relating to teachers who appear uncooperative and unconcerned about their child's dyslexia (Karande et al., 2009). Athira, Ismil, Haruna and Balakrishnan, (2018) stated that parents usually faced major challenges in dealing with dyslexic children. 'Difficult yet enduring' was a theme relating to time constraints, together with a lack of knowledge, increased financial demands, school issues, negative feeling towards the child's condition, the highly demanding role of the mother and changes in life pattern. Having a dyslexic child can result in chronic stress for parents, leading to negative parenting practices and adversely affecting parent-child relationships (Karande \& Kuril, 2011). A lower attachment to parents shown by students with dyslexia may be due to a higher load of schoolwork straining the relationships within the family. This is then affected by higher parental distress related to the perception of having a relationship with a 'difficult child' (Bonifacci et al., 2014). Mothers may face more challenges and they have to be mentally and physically prepared to cope with them. A failure to manage such challenges affects not only the mothers, but also their dyslexic children.

\section{METHOD}

\subsection{Sample data collection}

A sample survey was implemented and fifteen mothers of dyslexic children were selected with purposive sampling, nominated by child psychiatrists and teachers from four special education units in schools. All sample participants were mothers. There were 15 mothers of dyslexic children, (Experimental Group (EG) and 15 mothers of non-dyslexic children (Control Group (CG). All were mothers of children in grades 5-8, aged 10-14.

Instruments: A questionnaire and unstructured interviews were used for the study, together with a self-developed screening test for psycho-social issues and the Parental Stress Scale (Berry \& Jones, 1995) which is an 18 item self-report scale. The respondents agreed or disagreed in terms of their typical relationship with their child or children. A five-point scale (strongly disagree, disagree, undecided, agree, strongly agree) was used to score the level of parental stress. The scale was relatively short and easy to administer-it can be completed in less than 10 minutes. Overall possible scores on the scale range from 18-90. The higher the score, the higher the measured level of parental stress. The reliability coefficients as measured by Cronbach's alpha for the scale was calculated at $(\alpha=.82)$ Based on the literature, the selfdeveloped questionnaire was used to measure the mothers' emotional experiences. In this study, reliability reached $(\alpha=$ .78). The parents' stress scale was translated into Sinhala by psychology professionals. Informed consent and permission 
were obtained from mothers and the school authorities for all the participants. Ethical clearance was approved by the faculty research committee of the Faculty of Education Data analysis was done with percentages, paired sample t-test and unstructured interview results coded as statements.

\section{RESUTLS AND DISCUSSION OF THE STUDY}

Of the fifteen mothers of dyslexic children, eight (or 53\%) worked in the government and non-government sectors while seven (or 47\%) were housewives. Of the mothers of nondyslexic children, six (or 40\%) were working mothers and nine (or $60 \%$ ) were housewives.

Table 1Both the Mothers' Groups' Emotional Experience with the Child

\begin{tabular}{|c|c|c|c|c|c|}
\hline \multirow{2}{*}{ Item of Emotions } & \multicolumn{2}{|c|}{ EG } & \multicolumn{2}{c|}{ CG } & \multirow{2}{*}{ P } \\
\cline { 2 - 5 } & Mean & SD & Mean & SD & \\
\hline $\begin{array}{c}\text { Feelings of guilt } \\
\text { about the child }\end{array}$ & 8.67 & 1.20 & 1.24 & .931 & .00 \\
\hline $\begin{array}{c}\text { Fear for the child's } \\
\text { future }\end{array}$ & 7.65 & 2.26 & 2.60 & 1.09 & .00 \\
\hline $\begin{array}{c}\text { Sad feelings about } \\
\text { the child }\end{array}$ & 8.27 & 3.20 & 1.34 & .869 & .00 \\
\hline Frustration & 8.65 & 2.68 & 3.50 & 1.17 & .00 \\
\hline Anger & 3.50 & .963 & 2.51 & 1.06 & .04 \\
\hline $\begin{array}{c}\text { Restlessness } \\
\text { because of the child }\end{array}$ & 9.00 & 2.13 & 2.45 & 1.27 & .00 \\
\hline $\begin{array}{c}\text { Embarrassment } \\
\text { because of the child }\end{array}$ & 7.51 & 1.29 & .00 & .00 & .00 \\
\hline $\begin{array}{c}\text { Excessive worry } \\
\text { about the child's } \\
\text { nature }\end{array}$ & 9.50 & 1.36 & 2.56 & 1.41 & .00 \\
\hline $\begin{array}{c}\text { Happy about the } \\
\text { child's progress }\end{array}$ & 1.50 & .876 & 8.51 & 2.98 & .00 \\
\hline $\begin{array}{c}\text { Enjoying a relaxed } \\
\text { life with the child }\end{array}$ & 1.65 & .913 & 7.56 & 3.01 & .00 \\
\hline
\end{tabular}

Source: research data, 2021

According to Table 1, excessive worry about the child's nature $\mathrm{EG}(\mathrm{M}=9.50, \mathrm{SD}=1.36) \quad \mathrm{CG} \quad(\mathrm{M}=2.56, \mathrm{SD}=1.41)$ $\mathrm{p}<.001$; restlessness because of the child EG ( $\mathrm{M}=9.00, \mathrm{SD}=$ 2.13) $\mathrm{CG}(\mathrm{M}=2.45, \mathrm{SD}=1.27) \mathrm{p}<.001$; feeling of guilt about the child $(\mathrm{EG}=\mathrm{M}=8.67, \mathrm{SD}=1.20) \mathrm{CG}(\mathrm{M}=1.24, \mathrm{SD} .931)$ $\mathrm{p}<.001$; sad feelings about the child $\mathrm{EG}(\mathrm{M}=8.27, \mathrm{SD}=3.20)$ CG $(\mathrm{M}=1.34, \mathrm{SD}=.869) \mathrm{p}<.001$; presented as the prominent emotional experience factors negatively affecting significantly, the mothers of children with dyslexia, in contrast to the mothers of non-dyslexic children. Embarrassment because of the child $\mathrm{EG}(\mathrm{M}=7.51, \mathrm{SD}=1.29) \mathrm{CG}(\mathrm{M}=0.00$, $\mathrm{SD}=.000) \mathrm{P}<.001$ and the mothers' fear for the child's future EG $(\mathrm{M}=7.65, \mathrm{SD}=2.26) \quad \mathrm{CG} \quad(\mathrm{M}=2.60, \mathrm{SD}=1.09) \quad \mathrm{P}<.001$ seventh and eight level of negative emotions affected the mothers of dyslexic children in contrast to the mothers of nondyslexic children. According to the data of Table 1 it can be concluded that the mothers of dyslexic children presented negative emotions, with low scores in positive emotions, in contrast to the mothers of non-dyslexic children. These finding are line with previous studies done by Ozonoff, Dawson, and McPartland, (2002); Karande et al., (2009); Chandramuki et. al.,, (2012); Earey, (2013); Bonifacci et al.,
(2014) and Athira et. al., (2018).

According to Figure 1, the mothers of dyslexic children presented a significant relationship with stress and associated stress factors. Regarding Class teacher's role affecting the mothers, the results were: $\mathrm{EG}(\mathrm{M}=14.7, \mathrm{SD}=1.62) \mathrm{CG}(\mathrm{M}=$ $3.55, \mathrm{SD}=1.02) \mathrm{P}<$. 001; Regarding Doing school homework with child and how this affect the mothers', the results were :EG $(\mathrm{M}=18.00, \mathrm{SD}=3.2) \mathrm{CG}(\mathrm{M}=6.00, \mathrm{SD}=1.34) \mathrm{P}<.001$; Regarding the 'how child's problem with memory affect the mother, the results were: $\mathrm{EG}(\mathrm{M}=12.5, \mathrm{SD}=2.2) \mathrm{CG}(\mathrm{M}=4.00$, $\mathrm{SD}=.658) \mathrm{P}<.001$, Regarding 'Difficulty in accepting the reality of the child's nature,' the results were: ( $E G(M=12.5$, $\mathrm{SD}=2.06) \mathrm{CG}(\mathrm{M}=2.00, \mathrm{SD}=.563) \mathrm{P}<.001$; Regarding 'The differences between the two groups of mothers regarding their social isolation because of the child', the results were: EG $(\mathrm{M}=5.50, \mathrm{SD}=1.21) \mathrm{CG}=(\mathrm{M}=1.51, \mathrm{SD}=.682)$ respectively. According to the finding shown in Figure 1, the stress factors presented significantly higher mean scores for the mothers of dyslexic children, in contrast to the mothers of non-dyslexic children. These findings are line with studies done by Belsky (1984), Karande and Kuril (2011) and Elliott et al. (2016).

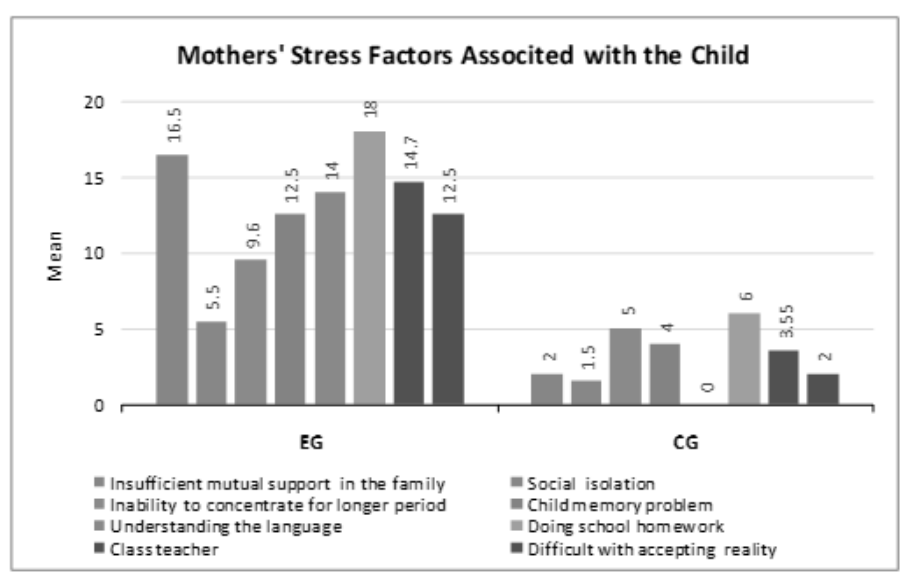

Fig. 1 Mothers' Stress Factors associated

Source: research data, 2021

According to the mothers' stress scale data analysis, the mothers of dyslexic children presented a moderate level of stress. The scores included the middle level of mean scores $(\mathrm{M}=34.51, \mathrm{SD}=10.92)(18-48)$. The range of the stress scores in the original scale was (18-90), representing mild to severe. The mothers of non-dyslexic children did not present stress and their score range was $(\mathrm{M}=12.26, \mathrm{SD}=9.86)$ stress score $(18<)$. These finding are in line with previous studies done by Karande and Kulkarni (2009) and Shyam and Govil (2014).

According to Figure 2: Regarding 'Mothers' satisfaction about their child', very lo scores were presented by the mothers of dyslexic children, as compared to the mothers of non-dyslexic children. The results were: "I am happy in my role as a parent" $\mathrm{EG}(\mathrm{M}=2.60, \mathrm{SD}=.832) \mathrm{CG}(\mathrm{M}=10.5, \mathrm{SD}$ 2.67) $\mathrm{P}<.001$; "I feel close to my child" $\mathrm{EG}(\mathrm{M}=3.20$, $\mathrm{SD}=.564) \mathrm{CG}(\mathrm{M}=9.00) \mathrm{SD}=1.20) \mathrm{P}<.001$; "I enjoy spending 
time with my child" $\mathrm{EG}(\mathrm{M}=2.50, \mathrm{SD}=.961) \mathrm{CG}(\mathrm{M}=9.50$, $\mathrm{SD}=1.03)$; "My child is an important source of affection for me" EG $(\mathrm{M}=1.60, \mathrm{SD}=.521) \quad \mathrm{CG}=(\mathrm{M}=8.50, \mathrm{SD}=2.11)$ respectively. The findings showed that the mothers of nondyslexic children were more satisfied in their motherhood as compared to the mothers of dyslexic children. These findings are in line with studies by Bonifacci et al. (2014), Earey (2013), Athira et. al. (2018).

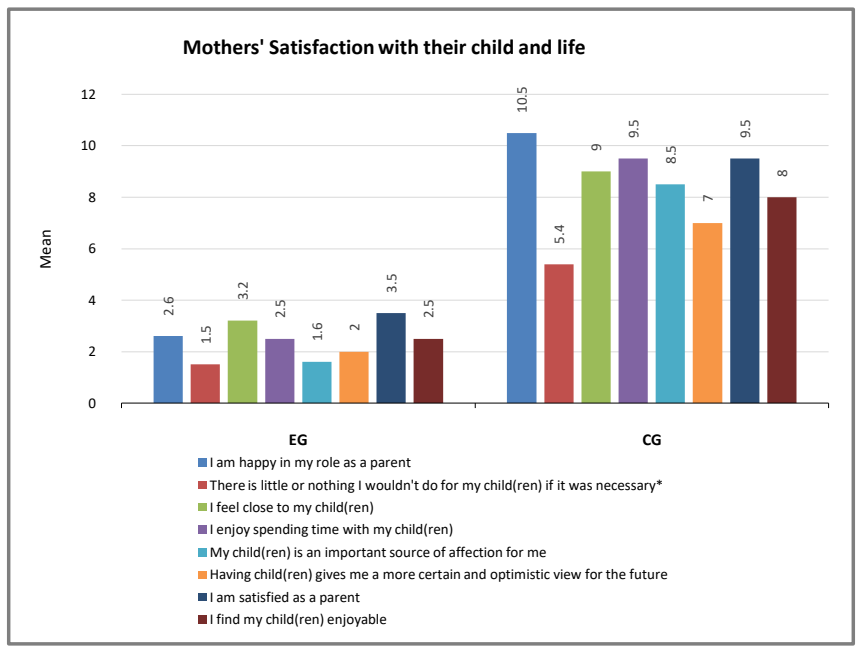

Fig 2. Mothers' Satisfaction with their Child and their Life

Source, Research data, 2021

The unstructured interview was conducted with the mothers of dyslexic children to identify their psycho-social experiences and the results showed that these mothers presented negative attitudes: five reported that they had irrational beliefs like: "If I had not worked so hard in my job during my pregnancy this would not have happened". Three mothers said, "If I had not had an induced labor then all would be ok". The mothers of dyslexic children accepted the situation and seven mothers said that according to their religious beliefs, "This is what "God wishes". Three mothers said "Karumaya, so I accepted this child". The mothers had positive attitudes as well. Six of the mothers of dyslexic children explained "I wish to care for my child and try to develop his education, at least I am grateful that dyslexia is not as bad compared to the other disabilities, my son has only reading difficulties, but his physical appearance is nice", but two mothers said that "life was bitter with a child with dyslexia". The mothers further stated that social stigma was the most difficult factor, making it hard to cope with their life.

"Disability child, stupid child with school works." Mothers of non-dyslexic children were mentioned that they can cope up children's issues. According to the findings of the unstructured interviews, it can be concluded that the mothers of dyslexic children face more psycho-social issues than the mothers of non-dyslexic children.

\subsection{Conclusion and Suggestions}

The mothers of dyslexic children presented higher levels of negative emotional experiences relating to their children's dyslexic nature, their education and their future, compared to the mothers of non-dyslexic children. Significant correlations with stress and associated stress factors could be seen for the mothers of dyslexic children. Some of the highly significant factors for the mothers of dyslexic children when contrasted to the mothers of non-dyslexic children included: insufficient mutual support in the family, class teachers' role, accepting reality, social isolation, the child's difficulties with learning, memory problems and problems with homework. The mothers of dyslexic children presented moderate level stress scores compared to the mothers of non-dyslexic children. The responses relating to parental life and satisfaction with their child showed very low scores for the mothers of dyslexic children, compared to the mothers of non-dyslexic children. Regarding 'Happy in my role as a parent', 'Enjoy spending time with the child', and 'Feel close to the child and have a close relationship', the mean scores were insignificantly higher for the mothers of non-dyslexic children, as compared to the mothers of dyslexic children. The mothers of dyslexic children had more negative attitudes than the mothers of nondyslexic children. The findings indicated that the mothers of dyslexic children need support and assistance to overcome their challenges and enhance their coping strategies and to protect and nurture their dyslexic children. These mothers need support from multi-disciplinary health professionals who can provide assistance through counselling, psychotherapy, psychological skills, occupational therapy and psychiatric treatment which would help them in parenting their children. Teachers and special education teachers should help the parents and their children to manage and overcome difficulties in reading, writing, and learning.

\section{REFERENES}

[1] Athira, A. A. R., Ismil, M. A., Haruna, K., \& Balakrishnan, V. (2018). Dyslexic children: The need for parents' awareness. Journal of Education and Human Development, 7(2): 91-99.

[2] Belsky J. (1984). The determinants of parenting: A process model. Child Development, 55(1): 83-96.

[3] Berry, J. D., \& Jones, W. H. (1995). The Parental Stress Scale: initial psychometric evidence. Journal of Social and Personal Relationships, 12, $463-472$.

[4] Bonifacci, P., Montuschi, M., Lami, L., \& Snowling, M. J. (2014). Parents of children with dyslexia: Cognitive, emotional and behavioral profile. Dyslexia, 20(2), 175-190. doi:10.1002/dys.1469

[5] Campbell, R., \& Butterworth, B. (1985). Phonological dyslexia and dysgraphia in a highly literate subject: A developmental case with associated deficits of phonemic processing and awareness. The Quarterly Journal of Experimental Psychology Section A, 37(3), 435-475.

[6] Chandramuki, D., Venkatakrishnashastry, I., \& Vranda, M. N. (2012). Attitudes of parents towards children with specific learning disabilities. Disability, CBR \& Inclusive Development. 23(1), 63-69.

[7] Dyson, A. (1997). Social and educational disadvantage: reconnecting special needs education. British Journal of Special Education, 24(4), 152-157.

[8] Earey, A. (2013). Parental experiences of support for pupils with dyslexia: Ignoring the effect on parents. Support for Learning, 28 (1), 35-40. doi:10.1111/14679604.12013

[9] Elliott, J., Nicolson, R., \& Davis, A. (2016). Dyslexia: Developing the debate. London: Bloomsbury. 
[10] Hamid, J. (2012). A web-based screening system for dyslexic pupils: Do teachers need it? i-Manager's Journal on Educational Psychology, 5(4), 15.

[11] Karande, S., Kumbhare, N., Kulkarni, M., \& Shah, N. (2009). Anxiety levels in mothers of children with specific learning disability. Journal of Postgraduate Medicine, 55 (3), 165-170. doi:10.4103/0022-3859.57388

[12] Karande, S., \& Kulkarni, S. (2009). Quality of life of parents of children with newly diagnosed specific learning disability. Journal of the Postgraduate Institute of Medicine 55(2), 97-103.

[13] Karande, S., \& Kuril, S. (2011). Impact of parenting practices on parent-child relationships in children with specific learning disability. Journal of Postgraduate Institute of Medicine, 57(1),
20-30.

[14] Ozonoff, S., Dawson, G., \& McPartland, J. C. (2002). A parent's guide to Asperger syndrome and high-functioning Autism: How to meet the challenges and help your child thrive: Guilford Press.

[15] Poon-McBrayer, K. F., \& McBrayer, P.A. (2014). Plotting Confucian and disability rights paradigms on the advocacyactivism continuum: Experiences of Chinese parents of children with dyslexia in Hong Kong. Cambridge Journal of Education, 44(1), 93-111.

[16] Shyam, R., \& Govil, D. (2014). Stress and family burden in mothers of children with disabilities. International Journal of Interdisciplinary and Multidisciplinary Studies, 1(4), 152-159. 